\title{
Successful treatment of a patient with recurrent infection of Chromobacterium violaceum
}

\author{
Lijuan Lang $^{1 \dagger}$, Menglei Wang ${ }^{1 \dagger}$, Xiaowen Huang ${ }^{1 \dagger}$, Hao Zhou², Zaigao Zhou', Liang Huang ${ }^{1}$, Huanxin Zheng ${ }^{1}$, \\ Kang Zeng ${ }^{1 *}$ and Li Li $i^{*}$
}

\begin{abstract}
Background: Chromobacterium violaceum (C. violaceum) is a Gram-negative saprophytic bacterium that is widespread in tropical and subtropical environments, and belongs to conditional pathogenic bacteria. Human infection with $C$. violaceum is rare, and this can be fatal when the diagnosis and treatment are delayed, especially recurrent infection patients. Since clinicians lack the knowledge for C. violaceum, rapid diagnosis and early appropriate antimicrobial treatment remains challenging.

Case presentation: A 15-year-old male student was hospitalized for dark abscess, pustules, severe pain in both legs, and fever for 11 days. There were pustules with gray-white pus and red infiltrating plaques on the back, and the subcutaneous nodules could be touched in front of both tibias, with scab, rupture and necrotic tissue of the lower limb. The patient's condition rapidly progressed. Therefore, next-generation sequencing (NGS), pustular secretion and blood culture were concurrently performed. The final diagnosis for this patient was C. violaceum infection by NGS. However, no bacterial or fungal growth was observed in the pustular secretion and blood culture. After 4 weeks of treatment, the patient was discharged from the hospital without any complications associated with C. violaceum infection.

Conclusion: Rapid diagnosis and early appropriate antimicrobial treatment is the key to the successful treatment of $C$. violaceum infection, especially in patients with sepsis symptoms. This case highlights that NGS is a promising tool for the rapid diagnosis of $C$. violaceum infection, preventing the delayed diagnosis and misdiagnosis of $C$. violaceum infection in patients who tested negative for pustular secretion and blood culture.
\end{abstract}

Keywords: Chromobacterium violaceum, Infection, Next-generation sequencing, Antimicrobial treatment

\section{Background}

Chromobacterium violaceum (C. violaceum) is a Gramnegative facultative anaerobic bacteria, which is slender, motile, sporeless and rod-shaped [1]. Furthermore, its colony is round, medium-sized and uniformly smooth, and it produces a chemical antioxidant compound called

\footnotetext{
* Correspondence: nfpfkzk@126.com; npfklily@163.com

+Lijuan Lang, Menglei Wang and Xiaowen Huang contributed equally to this work.

'Department of Dermatology, Southern Medical University Nanfang Hospital, Guangzhou 510515, China

Full list of author information is available at the end of the article
}

violacein, which makes the colony dark purple or even black [2]. In addition, it naturally resides in soil and stagnant water in tropical and subtropical regions [3]. C. violaceum was first identified in 1881. In 1905, Woolley isolated C. violaceum from a diseased buffalo in the Philippines, and described its pathogenicity for the first time [4]. In 1927, Malaysia first reported human cases of infection [4,5]. More than 200 cases of infection with $C$. violaceum have been reported, and most of which are in Southeast Asia and the eastern United States [2, 6]. Pathogens enter through fractured or worn skin, causing

(c) The Author(s). 2021 Open Access This article is licensed under a Creative Commons Attribution 4.0 International License, which permits use, sharing, adaptation, distribution and reproduction in any medium or format, as long as you give appropriate credit to the original author(s) and the source, provide a link to the Creative Commons licence, and indicate if changes were made. The images or other third party material in this article are included in the article's Creative Commons licence, unless indicated otherwise in a credit line to the material. If material is not included in the article's Creative Commons licence and your intended use is not permitted by statutory regulation or exceeds the permitted use, you will need to obtain permission directly from the copyright holder. To view a copy of this licence, visit http://creativecommons.org/licenses/by/4.0/ The Creative Commons Public Domain Dedication waiver (http://creativecommons.org/publicdomain/zero/1.0/) applies to the data made available in this article, unless otherwise stated in a credit line to the data. 
local skin damage, urinary tract infection, pneumonia, severe sepsis with metastatic abscess, and septic shock, which rapidly develops to death due to multiple organ failure $[1,7,8]$. The next-generation sequencing (NGS) test uses high-throughput sequencing technology based on the BGISEQ-50/500 sequencing platform to analyze the microbial nucleic acid sequences in the samples, and identify suspicious pathogenic microorganisms by comparing with the nucleic acid sequences of existing microorganisms in the database. The detection range included 3446 bacteria (including 104 mycobacteria and 45 mycoplasma/chlamydia), 1515 DNA viruses, 206 fungi and 140 parasites with a known genome sequence. The detection process included the following: nucleic acid extraction, library construction, sequencing, information analysis, report interpretation, etc. We report a new case of bacteremia caused by $C$. violaceum. To the best of our knowledge, this is the first case, in which the patient successfully survived after being infected with $C$. violaceum for two times, and the first case, in which C. violaceum was diagnosed by NGS.

\section{Case presentation}

A 15-year-old male student was hospitalized for dark abscess, pustules, severe pain in both legs, and fever for 11 days (Fig. 1A, B and C). The patient developed pustules on both legs after scratching while working in the field, and this was accompanied by chills and fever, with a maximum temperature of $40^{\circ} \mathrm{C}$. Then, the pustules spread to the abdomen, back and upper arms. The lower legs were markedly swollen, and the pustules at the ankles were broken and ulcerated, forming purple and black scabs. This patient was unable to walk and sit in a wheelchair due to pain.

\section{Physical examination}

There were pustules with gray-white pus and red infiltrating plaques on the back, and the subcutaneous nodules could be touched in front of both tibias, with scab, rupture and necrotic tissues of the lower limb. The liver and spleen did not touch. The patient's consciousness, cranial nerve motor system, sensory system reflex, meningeal stimulation sign, and autonomic nerve function were examined. No positive signs were found, and organic lesions of the nervous system and septic shock were excluded.

After admission, the following results were recorded: hemoglobin, $113 \mathrm{~g} / \mathrm{L}$; white blood cell (WBC) count, $20.83 \times 10^{9} / \mathrm{L}$; lymphocyte $(\mathrm{LYM})$ count, $0.52 \times 10^{9} / \mathrm{L}$; NEU, $19.75 \times 10^{9} / \mathrm{L}$; platelet (PLT), $112 \times 10^{9} / \mathrm{L}$; albumin (Alb), $30.00 \mathrm{~g} / \mathrm{L}$; erythrocyte sedimentation rate (ESR), $30 \mathrm{~mm} /$ hour; C-reactive protein (CRP), $247.81 \mathrm{mg} / \mathrm{L}$. The enhanced computed tomography $(\mathrm{CT})$ of the chest revealed a slightly low-density shadow on the bilateral

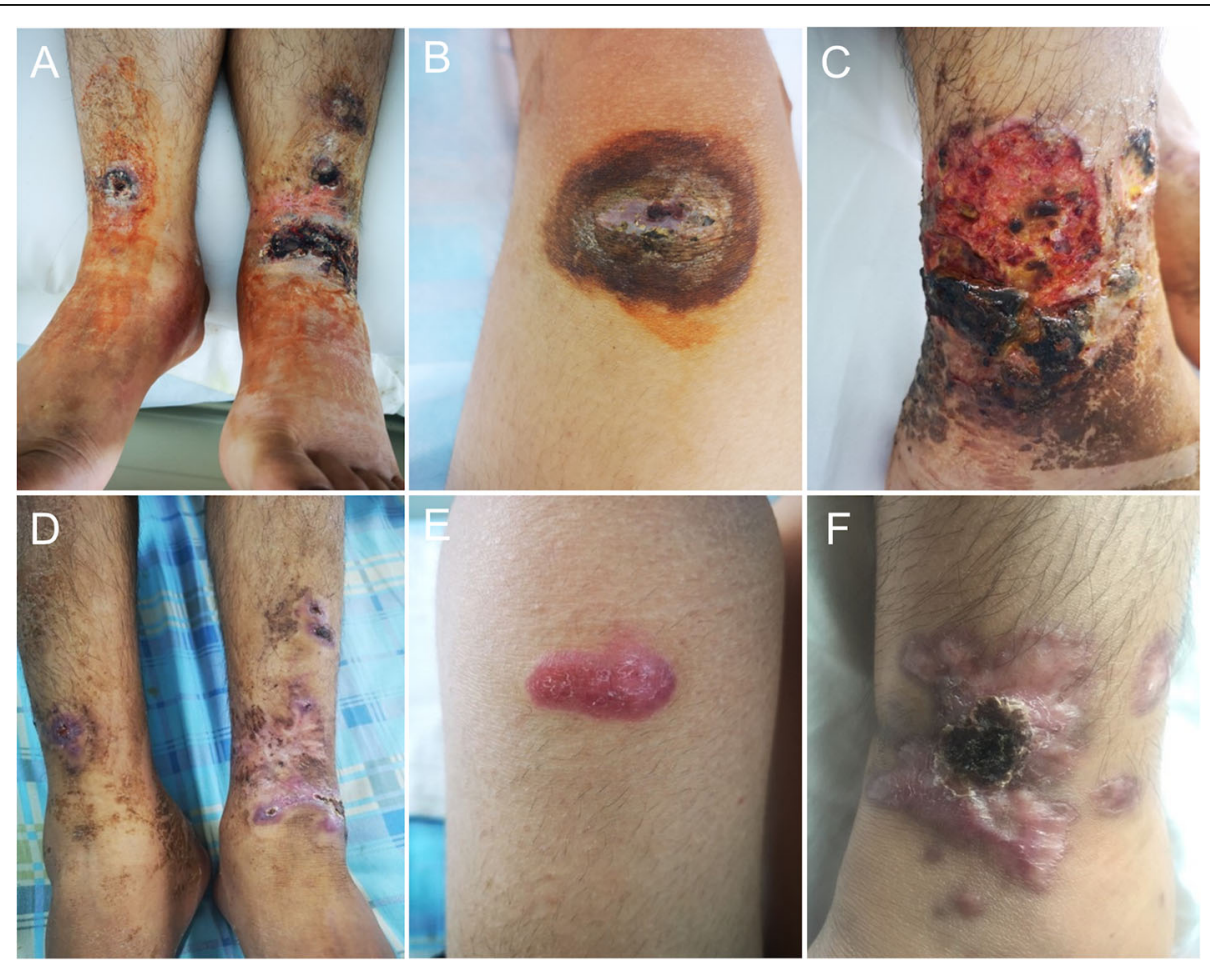

Fig. 1 A, B and $\mathbf{C}$ shows multiple ulcers of the lower limbs with erosion, scab and necrosis. D, E and $\mathbf{F}$ shows the ulcers that have healed, and the scar formation after treatment 
frontal and parietal subcutaneous, considering the possibility of abscess, and on the posterior mediastinal occupation, considering tumorous lesions, while lymphoma was not excluded (Fig. 2A). Furthermore, the autoantibodies, vasculitis binomial, human immunodeficiency virus (HIV) detection, purified protein derivative (PPD) test, T-SPOT, hypertrophy reaction, and fungal Dglucan were negative. The surgical biopsy of the back and abdomen revealed inflammation with abscess formation (Fig. 3). However, no bacterial or fungal growth was observed in the pustular secretion and blood culture. The NGS results for the tissue revealed the following detection sequence (Table 1), indicating that the patient was infected with $C$. violaceum. Hence, the investigators immediately switched to the experimental treatment of $0.4 \mathrm{~g}$ of amikacin VD, 12 per hour, and $1 \mathrm{~g}$ of meropenem IV, six per hour, supplemented with nutritional support. The patient provided the blood culture and drug sensitivity results at the time of hospitalization in 2016, which revealed that the lower limb pus culture was $C$. violaceum infection. The patient was contacted for more details on the 2016 hospitalization data, but the patient lost this information due to the long period of time. The antimicrobial tests revealed that this was sensitive to amikacin, gentamicin, meropenem, norfloxacin, cefepime, imipenem, minocycline, compound neonamine and levofloxacin, was intermediate-resistant to cefoperazone/sulbactam and aztreonam, and resistant to ceftazidime and piperacillin/tazobactam. The antibiotics chosen by the investigators was consistent with the drug sensitivity results. After 4 weeks of treatment, the patient's temperature dropped to the normal range. The chest enhanced CT re-examination revealed that the bilateral inflammatory nodules were absorbed, when compared pre-treatment. The re-examination for blood routine, erythrocyte sedimentation rate (ESR), C-reactive protein (CRP) and other indicators basically returned to normal. Furthermore, the whole body positron emission tomography-computed tomography (PET-CT) examination revealed that there were multiple enlarged lymph nodes in the left axilla, bilateral hilum and mediastinum (subcarinal lymph nodes). Moreover, the metabolism significantly increased, and some lesions in the left axilla were accompanied by calcification. It was suggested that lymphoma should be excluded by the biopsy of hypermetabolic lesions. Multiple nodular hypermetabolic lesions were observed in multiple parts of the patient's bones, and changes in bone density were considered to be correlated to infection. Multiple joints in the body have increased the metabolism, considering the multiple arthritis. In addition, hypermetabolism was observed in other parts of the body, and inflammatory lesions were considered (Fig. 2B and C). The patient's skin rash improved (Fig. 1D, E and F), and the patient went to an oncology hospital for further treatment.

\section{Discussion}

Although human infections caused by $C$. violaceum are rare, more than 200 cases have been reported worldwide [2]. The clinical manifestations of $C$. violaceum infection greatly vary, which ranges from mild fever, diarrhea, liver abscess, lung abscess, urinary tract infection and abdominal abscess, to rapid fatal sepsis [9]. The relevant clinical manifestations depend on the involved organs. The patient presented with high fever and occasional chills, severe pain in the whole body, and obvious tenderness in various parts of the body and joints, and was unable to walk. Patients with recurrent infection of $C$. violaceum that involve multiple parts and organs of the body are rare, especially cases that involve multiple bones and joints, which may be correlated to severe pain and the inability to walk.

C. violaceum is generally considered to be nonpathogenic [10], and immunodeficiency may be the potential cause of infection. Patients with chronic granulomatous disease and neutrophil dysfunction are

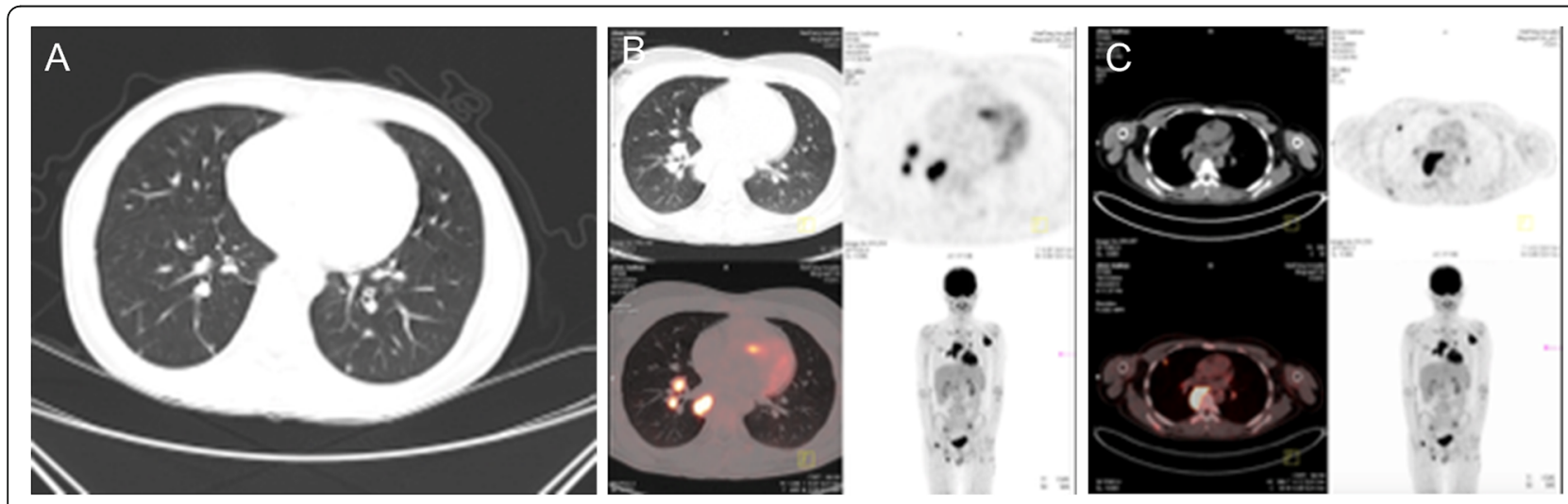

Fig. 2 A The computed tomography scan of the chest shows the posterior mediastinal occupation. B and C The positron emission tomographycomputed tomography scan reveals the hypermetabolic lesions in multiple parts of the body 


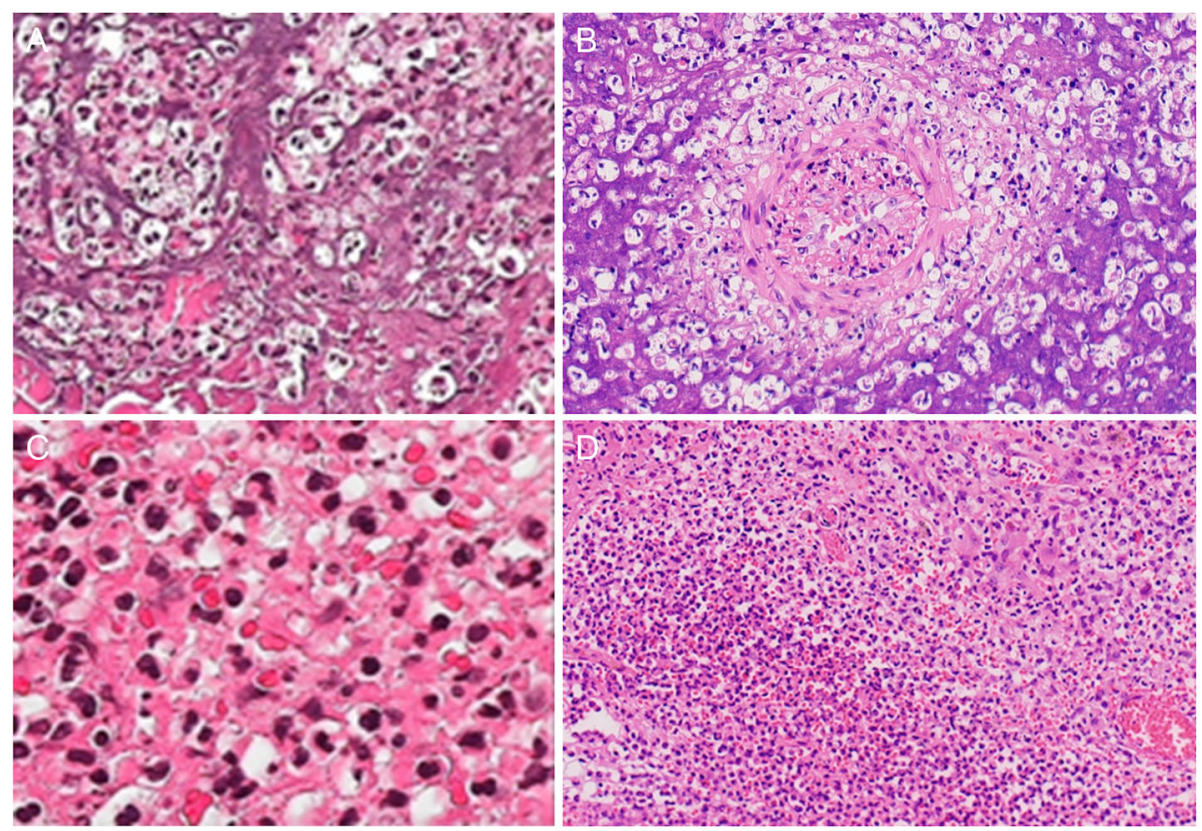

Fig. 3 The pathological images of the back, $\mathbf{A}(\times 400)$ and $\mathbf{B}(\times 100)$, and abdomen, $\mathbf{C}(\times 400)$ and $\mathbf{D}(\times 100)$, showing the inflammation with abscess formation

generally susceptible to C. violaceum infection [11]. The present patient was infected with this bacterium in 2016. After being hospitalized for nearly a month, the patient became better, and was discharged. Then, the patient was re-diagnosed with $C$. violaceum infection after 3 years. However, it could not be confirmed whether this was a recurrence caused by incomplete treatment at the first infection or reinfection. It is possible that the first antibiotic treatment course was inadequate, leading to recurrence. However, the patient's examination results took into account tumorous lesions, which may have some immune deficiencies that led to the reinfection.

Most cases are confirmed by bacteria cultured from body fluids and blood. To our knowledge, the present patient is the first confirmed case of C. violaceum infection by NGS, and the first case that successfully survived after infection with $C$. violaceum for two times. This is possibly due to the use of a large number of empirical antibiotics or other influences, and because $C$. violaceum could not be cultured in the patient's secretion, blood, urine and feces for a number of times. NGS is increasingly being used in the pathogen diagnosis of difficult and critical infections. This provides a new and effective approach for the diagnosis of infections with rapid progression and high mortality, such as C. violaceum. Due to the rare case of infection with $C$. violaceum, the mechanism of pathological damage remains unclear, and clinicians lack the knowledge of $C$. violaceum. As an

Table 1 The next-generation sequencing report

\begin{tabular}{lllll}
\hline Type & Category & Detection sequence & Species & Detection sequence \\
\hline $\mathrm{G}^{-}$ & Chromobacterium & 562 & Chromobacterium violaceum & 456 \\
$\mathrm{G}^{+}$ & Lactobacillus & 26 & Lactobacillus crispatus & 24 \\
$\mathrm{G}^{-}$ & Acinetobacter & 3 & - & - \\
$\mathrm{G}^{+}$ & Staphylococcus & 3 & - & - \\
Fungus & Malassezia & 8 & Malassezia japonica & 7 \\
Viruses & - & - & - & - \\
Parasite & - & - & - & - \\
M.tuberculosis & - & - & - & - \\
UU/CT & - & - & - & -
\end{tabular}

Notes: Detection sequence: The number of strictly aligned sequences of the microorganism detected at the genus/species level; -: Indicates that the information is not available; $\mathrm{G}^{+}$: Gram-positive bacteria; $\mathrm{G}^{-}$: Gram-negative bacteria 
emerging and "underdiagnosed" pathogen, there are no clinical diagnostic guidelines for C. violaceum. According to the cases reported in the literature, it was found that the increase in WBC, NEU, ESR and CRP, and the decrease in ALB are of diagnostic significance. However, the diagnoses evidence of this bacterium mainly depends on clinical manifestations and detection of infected bacteria. We report this case with the hope of helping clinicians further understand the infection of $C$. violaceum, and providing clinical information to improve the diagnosis and treatment of the $C$. violaceum infection.

\section{Conclusions}

The infections caused by Chromobacterium violaceum may be treated successfully, if prompt proper treatment is started. For this, the clinicians should be aware of rapid diagnosis will become crucial. Next-generation sequencing may offer higher sensitivity for pathogen detection, enabling earlier diagnosis and more targeted antimicrobial therapy.

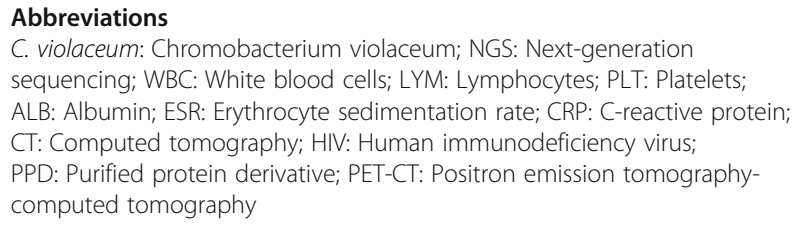

\section{Acknowledgements}

The authors gratefully acknowledge the patient for allowing the readers to learn from the medical condition of the patient, and allowing the authors to write the case report.

\section{Authors' contributions}

$K Z$ and $L L$ analyzed the data of the patient, and participated in the diagnosis. $L L$ was in charge of managing the data and writing the manuscript. ZGZ, MI W, LH and XW H were responsible for the clinical care of the patient, and the design of the manuscript. $\mathrm{HZ}$ collected the clinical data. All authors read and approved the final manuscript.

\section{Funding}

This work was supported by the Natural Science Foundation of Guangdong Province (2018A030313773). The funding body had no role in the design of the study and collection, analysis, and interpretation of data and in writing the manuscript.

\section{Availability of data and materials}

All data generated and analyzed during the study were included in the published article.

\section{Declarations}

Ethics approval and consent to participate

An approval from the ethics committee was not necessary for the reason that all data was acquired through tests conducted for clinical purposes. The patient signed an institutional informed consent for receiving treatments.

\section{Consent for publication}

A written informed consent was obtained from the patient's legal guardian(s) for the publication of this case report, and any accompanying images. A copy of the written consent is available for review by the Editorin-Chief of this journal.

\section{Competing interests}

The authors declare that they have no competing interests.

\section{Author details}

'Department of Dermatology, Southern Medical University Nanfang Hospital, Guangzhou 510515, China. ${ }^{2}$ Department of Infection Management, Southern Medical University Nanfang Hospital, Guangzhou 510515, China.

Received: 19 November 2019 Accepted: 20 May 2021

Published online: 26 May 2021

\section{References}

1. Sharmin S, Jahan AA, Kamal SMM, Sarker P. Fatal infection caused by Chromobacterium violaceum: a case report from a tertiary Care Hospital in Bangladesh. Case Rep Infect Dis. 2019;2019:6219295.

2. Khadanga S, Karuna T, Dugar D, Satapathy SP. Chromobacterium violaceuminduced sepsis and multiorgan dysfunction, resembling melioidosis in an elderly diabetic patient: a case report with review of literature. J Lab Phys. 2017:9(4):325-8. https://doi.org/10.4103/JLP.JLP_21_17.

3. Pant ND, Acharya SP, Bhandari R, Yadav UN, Saru DB, Sharma M. Bacteremia and urinary tract infection caused by Chromobacterium violaceum: case reports from a tertiary Care Hospital in Kathmandu, Nepal. Case Rep Med. 2017;2017:7929671.

4. Parajuli NP, Bhetwal A, Ghimire S, Maharjan A, Shakya S, Satyal D, et al. Bacteremia caused by a rare pathogen - Chromobacterium violaceum: a case report from Nepal. Int J Gen Med. 2016;9:441-6. https://doi.org/10.214 7/JGM.S125183.

5. Sneath PH, Whelan JP, Bhagwan Singh R, Edwards D. Fatal infection by Chromobacterium violaceum. Lancet. 1953;265(6780):276-7. https://doi. org/10.1016/s0140-6736(53)91132-5.

6. Dromigny JA, Fall AL, Diouf S, Perrier-Gros-Claude JD. Chromobacterium violaceum: a case of diarrhea in Senegal. Pediatr Infect Dis J. 2002;21(6):5734. https://doi.org/10.1097/00006454-200206000-00021.

7. Batista JH, da Silva Neto JF. Chromobacterium violaceum pathogenicity: updates and insights from genome sequencing of novel Chromobacterium species. Front Microbiol. 2017;8:2213. https://doi.org/10.3389/fmicb.2017. 02213.

8. Yang CH, Li YH. Chromobacterium violaceum infection: a clinical review of an important but neglected infection. J Chin Med Assoc. 2011;74(10):43541. https://doi.org/10.1016/j.jcma.2011.08.013.

9. Matsuura N, Miyoshi M, Doi N, Yagi S, Aradono E, Imamura T, et al. Multiple liver abscesses with a skin pustule due to Chromobacterium violaceum. Intern Med. 2017;56(18):2519-22. https://doi.org/10.2169/internalmedicine. 8682-16.

10. Brito CF, Carvalho CB, Santos F, Gazzinelli RT, Oliveira SC, Azevedo V, et al. Chromobacterium violaceum genome: molecular mechanisms associated with pathogenicity. Genet Mol Res. 2004;3(1):148-61.

11. Mamlok RJ, Mamlok V, Mills GC, Daeschner CW 3rd, Schmalstieg FC, Anderson DC. Glucose-6-phosphate dehydrogenase deficiency, neutrophil dysfunction and Chromobacterium violaceum sepsis. J Pediatr. 1987;111(6 Pt 1):852-4. https://doi.org/10.1016/S0022-3476(87)80203-2.

\section{Publisher's Note}

Springer Nature remains neutral with regard to jurisdictional claims in published maps and institutional affiliations.

\section{Ready to submit your research? Choose BMC and benefit from:}

- fast, convenient online submission

- thorough peer review by experienced researchers in your field

- rapid publication on acceptance

- support for research data, including large and complex data types

- gold Open Access which fosters wider collaboration and increased citations

- maximum visibility for your research: over 100M website views per year

At BMC, research is always in progress.

Learn more biomedcentral.com/submission 